\title{
DAYLIGHT TRANSMISSION ANALYSIS IN EXPERIMENTAL BUILDING ENVELOPE ASSEMBLIES
}

\author{
M. FAJKUS \\ The University of Texas at Austin School of Architecture, Austin, USA.
}

\begin{abstract}
In light of the fact that building envelope design and construction are critical for building performance as well as the fact that architects and engineers rarely collaborate in the early phases of design processes, the Facade Laboratory at The University of Texas at Austin was established. The laboratory exists as a physical chamber to allow testing in the areas of daylighting, thermal exchange, ventilation, and the use of direct and indirect solar energy. The full-scale size of the Facade Laboratory helps provide particularly accurate data, as the prediction of a structure's lighting and thermal behavior is inherently dependent on the use of real-scale testing facilities. Simultaneously, the data collected through experimentation with the Facade Laboratory is used in the calibration of energy simulation software. Physical facade mock-up tests inspire new speculative simulated tests and vice versa. An initial shading structure, Prototype 1, was designed, built, and tested virtually and physically. A second scheme, Prototype 2, tested only virtually thus far, expands upon the first scheme by proposing speculative hybrid light/ventilation filters which incorporate passive daylight to optimize building energy consumption, thus allowing for improved interior lighting conditions while simultaneously creating improved indoor air quality. The Facade Laboratory offers the opportunity to develop an integrated approach to problem solving by an interdisciplinary team of architectural and engineering students as well as professionals. Initial facade construction design and mock-up experiments as well as corollary virtual experiments have yielded interesting qualitative and quantitative results, warranting a larger discussion regarding their implications.

Keywords: Daylighting, interdisciplinary collaboration, shading device.
\end{abstract}

\section{INTRODUCTION}

In the evolutionary advancement of sustainable design considerations, building enclosure design and construction have become increasingly critical in the execution of optimal performance in terms of quantifiable sustainable efficiency as well as phenomenological performance. We spend an average of $90 \%$ of our time indoors, and the built environment that immediately surrounds us is influenced by many factors, including scale, proportion, materiality, light, and color. Historically, architectural research at universities has focused primarily on these physical aspects, while issues related to the performance of buildings was conducted by architectural and structural engineers and only rarely connected to spatial explorations. As buildings continue to consume nearly $40 \%$ of all the energy produced [1] and as our natural resources are becoming increasingly scarce, the architectural profession has recognized the need for more sustainable building practices. Practitioners have identified the potential impact that climatic conditions and the resulting performance requirements can have on the aesthetic qualities of our buildings, and are beginning to open a new venue for research in this field.

The ever-pressing issue of energy efficiency must also be balanced with consideration of the human condition and the critical relationship between the human body and the external environment. The human body has evolved around the conditions of natural daylight. Our circadian rhythms are rooted in the natural cycle of light and dark [2]. The best way forward for architectural design is to look back at our origins while testing and incorporating the latest technologies to optimize building envelope performance. The building envelope must strike an optimal balance between energy efficiency and spatial/formal perception. In terms of minimal internal energy use, the most 'efficient' building might have no openings at all, although such an internal environment would be far from 
desirable due to a complete lack of natural light and views. To maximize efficiency and perception of space, the transparent elements of a building are the most critical points for consideration, as these transparent surfaces are the primary conduit for thermal exchange as well as sunlight and daylight transmission. In addition to performing as the primary defining aesthetic feature of a building, the envelope provides an opportunity to enhance and expand upon our relationship with nature in terms of light, air, and views.

Air and light are two of the most fundamental elements to the existence of mankind, and both require a degree of filtration for human consumption in many cases. 'Filtration' is technically a removal or containment of at least a portion of elements before penetration of a given surface [3]. Two thousand years ago, Roman industries acknowledged and mitigated the dust problem, and calibrated daylight screens have existed since the Moorish Ahlambra of the 15th Century, with similar techniques of diffusing light tracing as far back as the 11th century in Islamic architecture. The Islamic screens, known as masharabiyyas, combine functionality with aesthetic and symbolic qualities, creating spatial separation, while the porosity of the screen allow cross-ventilation and light filtration [4]. The filtered light varies throughout the day both in direction and shape, adding complexity to the adjacent surfaces that capture the light and shadow, while varying lighting conditions within the space. Though air and light filtration developed as separate entities historically, they have not developed as a hybridized air/light modulation technique. Over the years, air quality control has fallen into the hands of engineers and daylight management into the realm of the architect, with no cross-pollination between the fields despite the interdependent relationship of the two.

However, in most facade design processes, aesthetic issues have been the primary concern of architects, while energy-efficiency optimization has been almost exclusively the role of architectural engineers, and even that rigorous analysis is extremely new to the profession in relative terms. Simulation software has begun to bridge that gap as a collaborative tool, and now the Facade Laboratory at The University of Texas has been established as a physical full-scale facade testing tool to compliment its digital counterparts. Balance and interaction between the two establishes a synergy and a loop between virtual and physical test scenarios for a singular design, as well as an interdisciplinary tool for both architects and engineers in the academy and the profession, to affect positive change in facade design energy optimization in addition to establishing parameters which can act as inspiration in formal and aesthetic decisions within tolerance margins.

\section{THE UNIVERSITY OF TEXAS FACADE LABORATORY: A QUANTITATIVE FACADE TESTING TOOL}

Based on the need to facilitate experimental research related to the improvement of building envelope performance and to compliment virtual simulation data, the Facade Laboratory was established at The University of Texas in late 2009 to allow testing of innovative building components and systems, pairing the quantitative analysis of energy performance with the qualitative analysis of space, aesthetics, and design (see Fig. 1). The Facade Laboratory consists of a full-scale, single room space with a south-facing facade, which allows for thermal experiments as well as testing in the areas of daylighting, ventilation, and the use of direct and indirect solar energy. The small test box with exterior dimensions of approximately $4 \times 5 \times 3 \mathrm{~m}(\mathrm{w} / \mathrm{d} / \mathrm{h})$ is located on top of a campus building. The facility is able to measure the effects of innovative cladding materials and shading systems, which inform the field of experimental research as it relates to sustainable building in two significant ways. First, as an important subsystem within a building, the building envelope's primary task is to regulate the external climate conditions to provide comfortable internal conditions for the occupants. As a result, the envelope's performance has a significant impact on a building's overall energy consumption and dramatically influences the load on mechanical building services. 


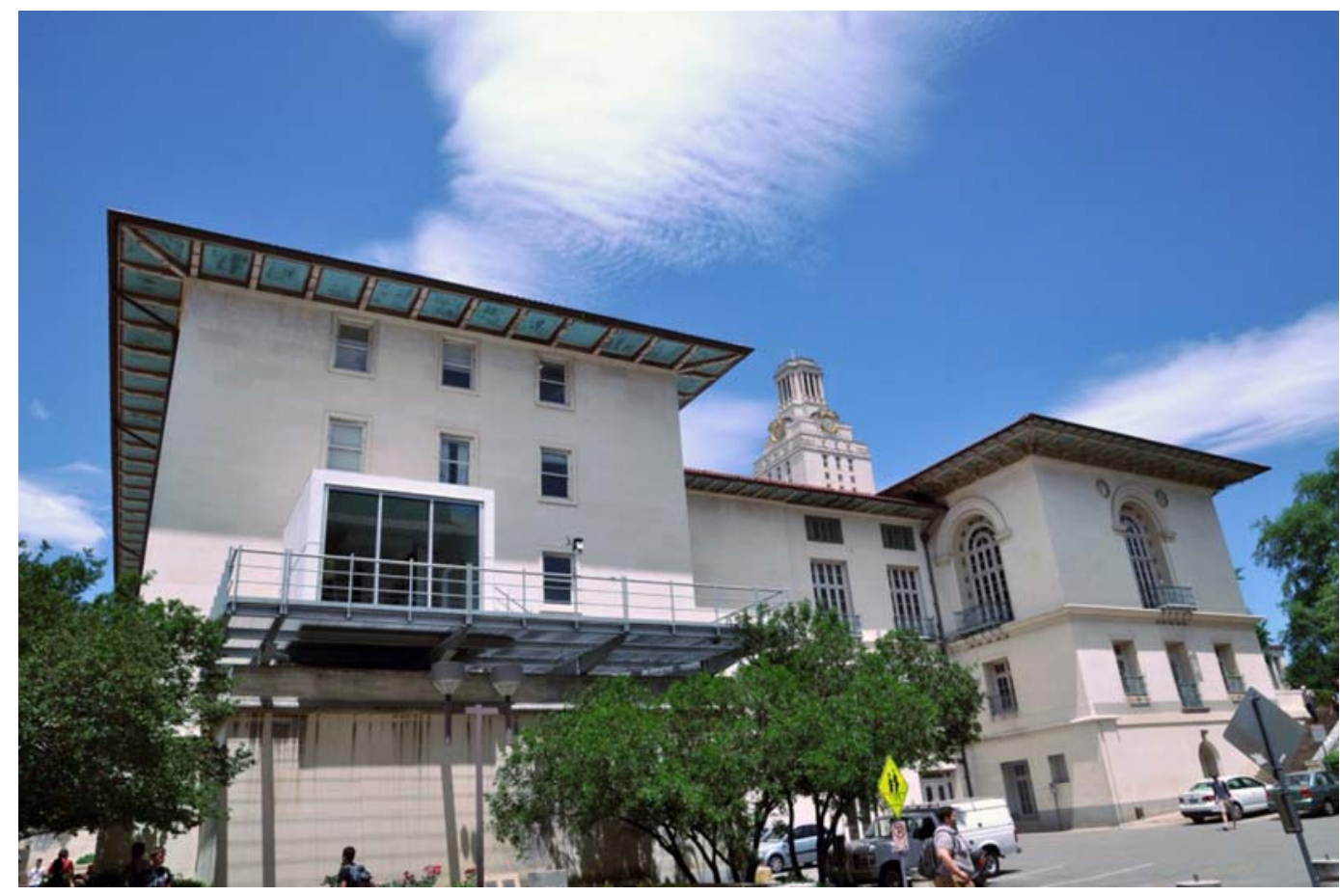

Figure 1: View of Facade Laboratory on platform.

Second, predicting a structure's thermal behavior is inherently dependent on the use of real-scale testing facilities, since the relationship between building volume and surface area is a crucial factor with regard to thermal gains and losses as well as energy demand, thus affecting internal comfort.

The Facade Laboratory allows for careful analysis of each interior plane (wall) of a space with a matrix of sensors which together provide remote readings of thermal and daylight data, as affected by any combination of shading device and climatic instance in time (see Fig. 2). For example, the ceiling plane, when properly illuminated by a light shelf or other reflective shading device, can carry light deep into a space, which is particularly important in commercial buildings with deep floor plates.

The laboratory also allows for experiments with different materials that yield varying results in terms of thermal property capacities. Metal, wood, and plastic have very different properties in terms of thermal storage capacity as well as reflectance, as noted by Schittich [5], which can be measured quantifiably by the laboratory. For this particular research and prototypical design, daylight was the measured element of focus, as thermal impact calculations were not performed.

\subsection{Basis for experimental physical test case (prototype 1)}

As an initial example of The University of Texas Facade Laboratory's potential as a tool for design and experimentation, a shading device prototype was designed and developed by Stefan Bader, a student in the Master of Sustainable Design Studies program, under advisor Professor Dr. Werner Lang. Starting in early 2010, the design set out to achieve a shading structure which would maximize efficiency as well as internal comfort, daylight, and views. In addition to phenomenological aspects, 


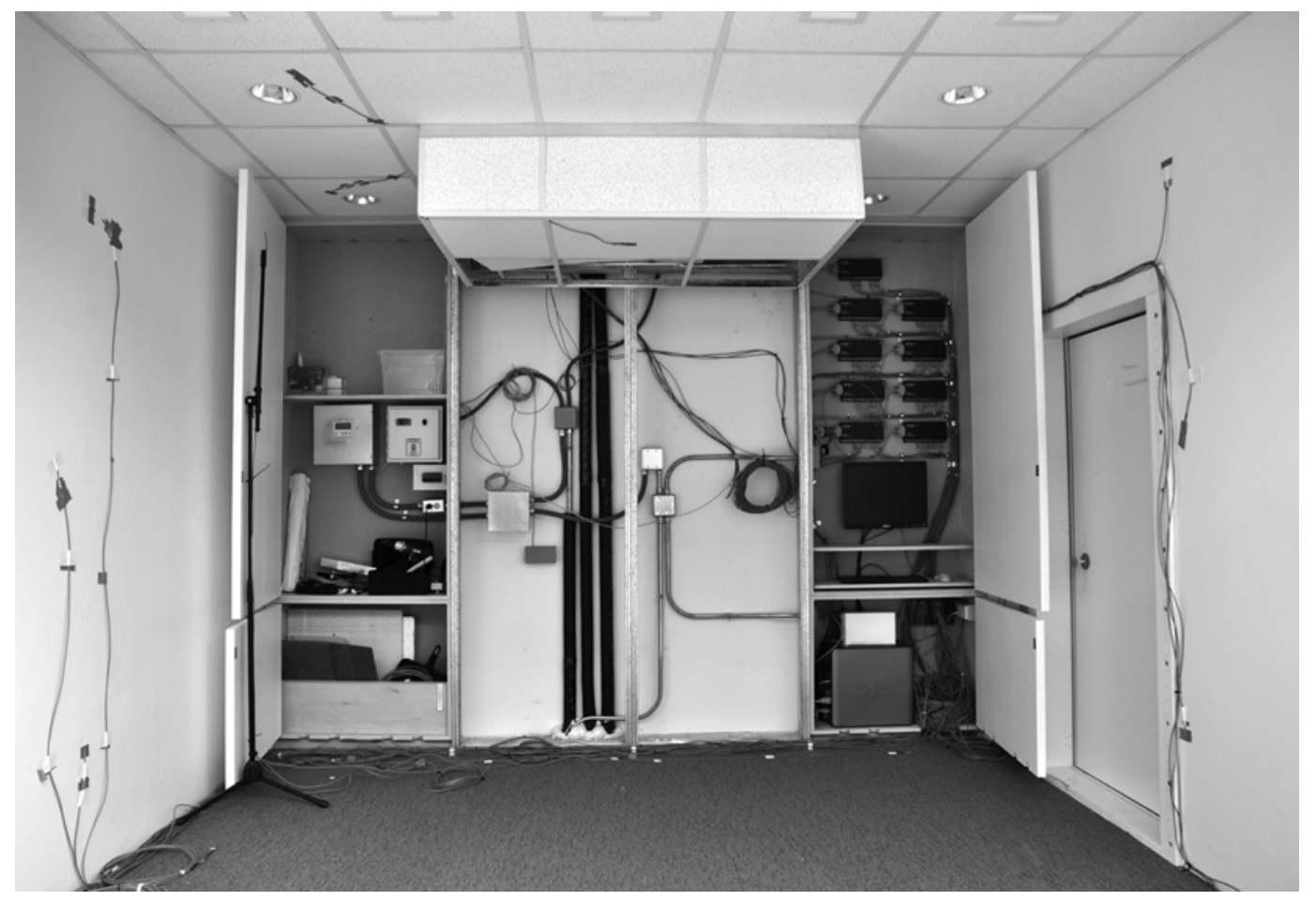

Figure 2: View of Facade Laboratory interior with remote sensor equipment.

the project aimed at high standards in regard to low energy use, by limiting cooling loads and demands for artificial lighting, while avoiding glare and winter heat loss. More specifically, the shading structure was intended to be a patterned array of fixed shading components, sharing an overall geometric logic but varying in size and proportion to fulfill desired criteria, such as views, transparency, as well as the aesthetic appearance of the structure itself in addition to its solar and thermal implications.

\subsection{Benchmarking to establish baseline parameters for prototype 1}

The Facade Laboratory allows for quantitative full-scale testing of conventional facade and shading systems, to establish baselines within the existing built environment. To be able to design optimized and innovative structures, it is critical to specifically understand conventional shading structures. Six generic benchmark shading structure types (see Fig. 3) were tested for solar radiation in the specific hot, humid Austin climate in which the Facade Laboratory exists, via digital simulation processes, and the results were documented in the research of Bader [6].

\subsubsection{Horizontal louvers (type A)}

The type of horizontal louvers tested in this study consists of blinds which are perpendicular to the surface. They have a depth and a distance between each blind of $30 \mathrm{~cm}$. They span over the entire width of the window (see Fig. 3a). The horizontal shading devices had a small improvement of $3.24 \%$ compared to southwest and $10.55 \%$ to the west. Horizontal louvers on the southwest 


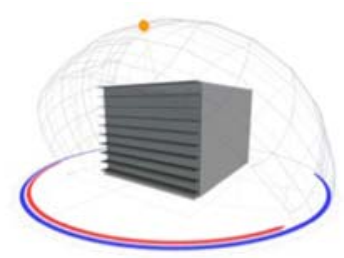

a)

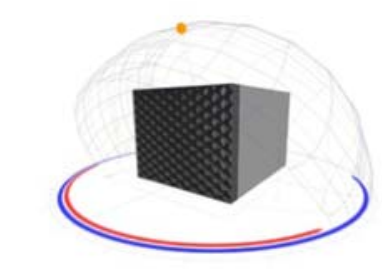

d)

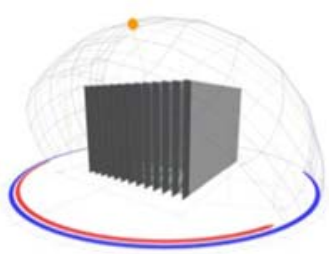

b)

Vertical shading dences

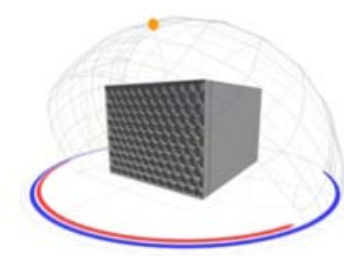

e)

Honeycomb shading structure - vertically

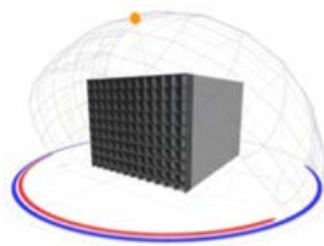

c)
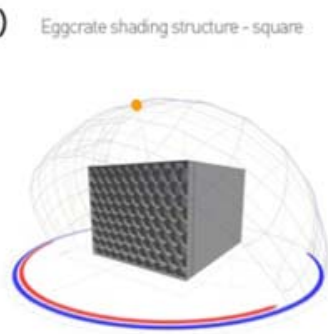

f)

mbang structure - vertically

Figure 3: Generic conventional shading device benchmarks.

allow $7.31 \%$ more solar radiation than for a west-orientated surface. Horizontal louvers have a minimum shading coefficient (sc) of 0.47 (west) (see Fig. 4).

\subsubsection{Vertical louvers (type B)}

The design of the vertical blinds has a depth and a distance between each blind of $30 \mathrm{~cm}$ and covers the entire height of the window wall (see Fig. 3b). Vertical shading devices on west-orientated surfaces provide $10.10 \%$ less shading than on the south and also $2.85 \%$ less than on the southwest. Compared to horizontal louvers, vertical blinds can only provide a minimum sc of 0.68 (west), no matter the orientation (see Fig. 4).

\subsubsection{Eggcrate shading structure (type C)}

Eggcrate shading structures are a combination of the horizontal and vertical blinds as described before. The square type is designed with an opening of $30 \mathrm{~cm}$ width/height and a depth 0 $30 \mathrm{~cm}$ (see Fig. 3c). South-orientated eggcrate shading structures deliver the best results with regard to shading. With $4.84 \%$ more shading in south than southwest and even $11.57 \%$ more shading than west, eggcrate shading structures show a minimum shading coefficient (sc) of 0.39 (west) in all orientations (see Fig. 4).

\subsubsection{Horizontally orientated shading structures (type D)}

The honeycomb structure consists of symmetrical hexagonal components with a depth of $30 \mathrm{~cm}$. They have a diameter of $30 \mathrm{~cm}$ and a circumference of $9 \mathrm{~cm}$, resulting in $20 \mathrm{~cm}$ long edges. The maximum component height is $34 \mathrm{~cm}$. These honeycombs are wider than tall. They have two horizontal edges (see Fig. 3d). Similar to eggcrate structures, this type performs best in south. It provides $5.12 \%$ more shading than southwest and $10.70 \%$ more shading than west. With a minimum sc of 0.38 (west), this type of honeycomb has a similar behavior as an eggcrate type (see Fig. 4). 


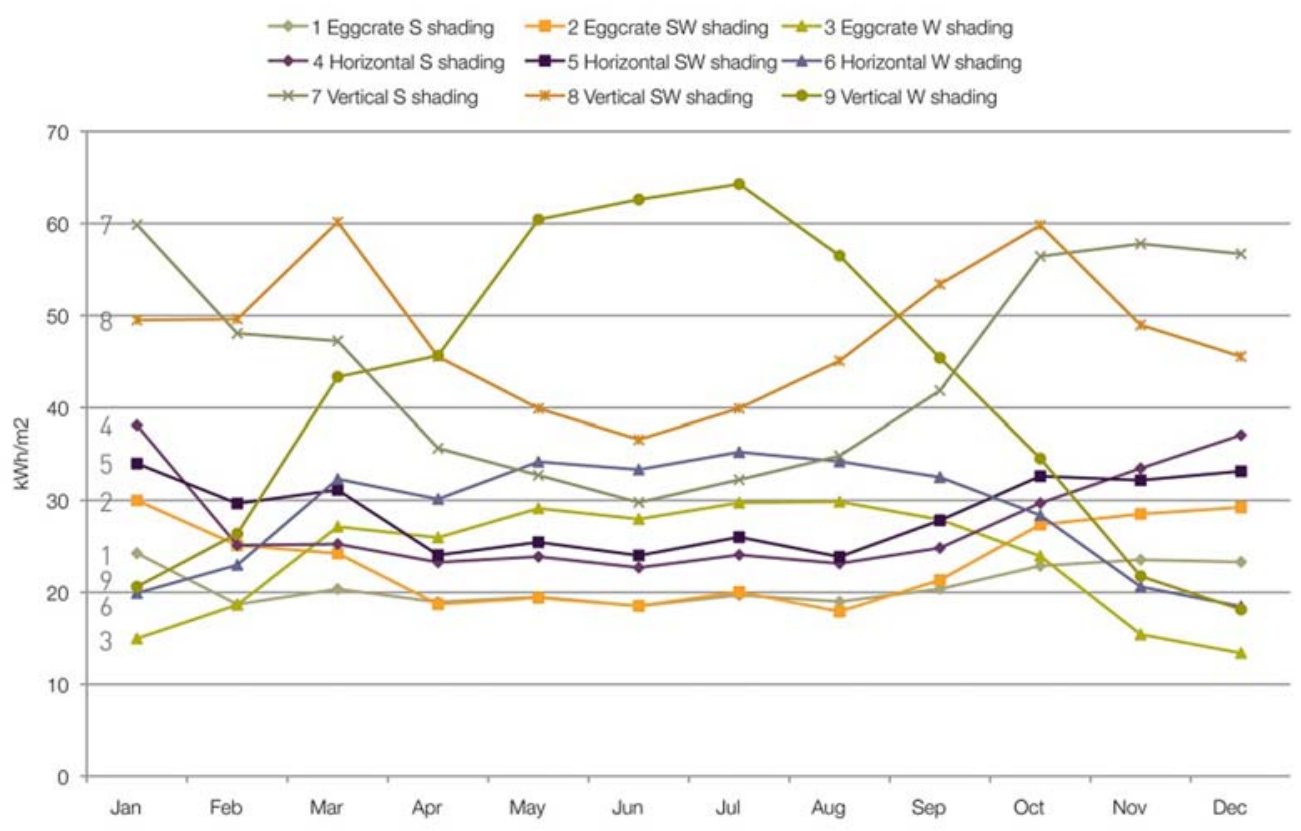

Figure 4: Monthly solar radiation comparison of benchmark shading devices.

\subsubsection{Vertically orientated shading structures (type E)}

This structure is similar to a horizontally orientated honeycomb but rotated by 90 degrees. Thus, the components are taller than wide and have two vertical edges (see Fig. 3e). This honeycomb, orientated toward south, performs best of all honeycomb structures in type and orientation. With a sc of 0.27 , it is slightly better but performs similar on south as the horizontally orientated type. It performs $4.50 \%$ (southwest) and $10.65 \%$ (west) better than in the other orientations. The minimum sc is 0.38 (west). Comparing the percentages of horizontally and vertically orientated honeycomb structures, it can be concluded that a change of its orientation has a slight impact on the shading performance. In general, vertically orientated honeycombs perform better than horizontally oriented types (see Fig. 4).

\subsubsection{Vertically orientated honeycomb w/1.4 m circumference (type F)}

The third variation of the honeycomb structure has a circumference equal to the sum of the sides of the square openings of the eggcrate structure, which is $1.4 \mathrm{~m}$. Thus, this honeycomb structure is actually bigger than types 4 or 5 (see Fig. 3f). Similar, but with 3.69\% (type 4) and 3.91\% (type 5) less provided shading than other honeycomb types, this type also has its best performance on a south-orientated surface. As expected, it performs in every direction slightly worse than the other types. Compared to the south, this type provides $5.49 \%$ less shading in southwest and $11.64 \%$ in west (see Fig. 4).

\section{DESIGN METHODS/GOALS FOR PROTOTYPE 1 (OPTIMIZED HONEYCOMB VARIANT)}

The design of the experimental shading device (prototype 1) began with thorough research including a rigorous analysis of the times when sun shading is needed at the given geographic coordinates and south-facing orientation, and the surface needs of a shading device, based on an understanding 

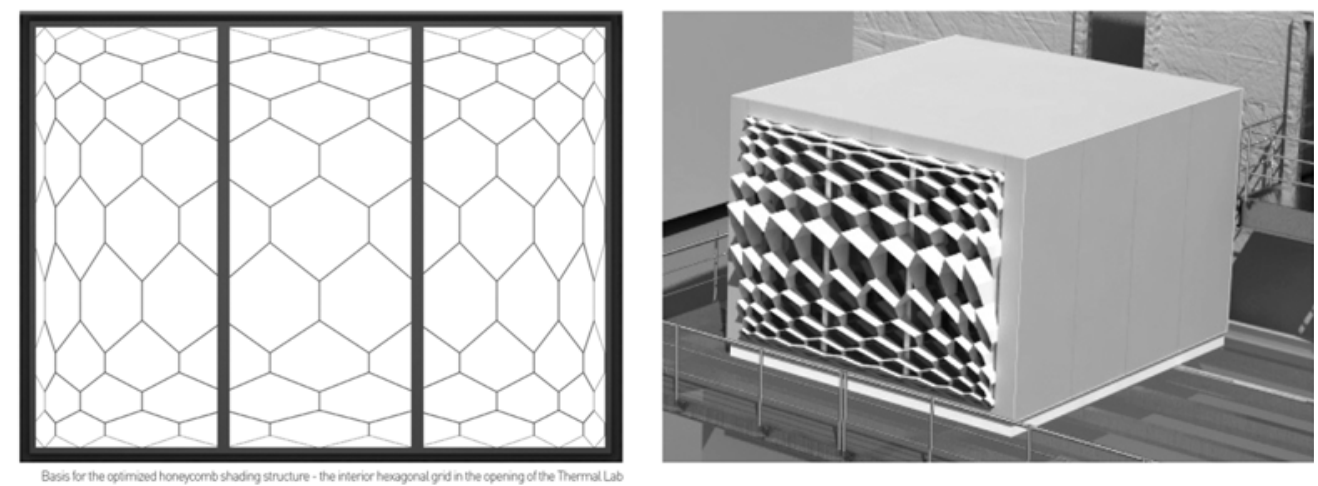

Figure 5: Virtual development of experimental prototype structure.

of the local sun path, as spelled out by Bader [6]. In the hot, humid climate of Austin, Texas, the summer exterior temperature is above the comfort level more often, and thus direct summer solar radiation frequently leads to overheating. In contrast, direct winter sunlight is desired to reduce heating loads and electrical consumption by artificial lighting. Therefore, the first shading prototype was designed to provide full shading in the summer and direct solar exposure in the winter, while existing as a static structure, as well as optimizing views out from the inside.

After carefully considering the advantages and disadvantages of each generic benchmark shading device type, a honeycomb variant was chosen as the general shape of the unit or module of the experimental prototypical shading device (see Fig. 5). This decision took into consideration solar performance as well as construction material assembly. First, the honeycomb form loosely mimics the semicircular daily path of the sun. Second, the hexagon shape is structurally more rigid than a rectangular form, due to its diagonal members which utilize the structural principle of triangulation. The pattern also uses a minimal amount of surface area to create a lattice of cells within a given volume and the hexagonal forms stack well to reduce material. Lastly, the novelty of the form was a driver in the pursuit to explore undocumented territory in shading device design, as noted by Bader [6].

\subsection{Prototype 1: Fabrication and comparative performance results}

The experimental prototype was cut out of polypropylene sheets with a Computer Numerical Control (CNC) Router and assembled in units (see Figs. 6-8). Results showed that the optimized honeycomb experimental prototype structure provides the lowest sc for south relative to conventional counterparts, but performs best for southwest and west. For south, the sc is provided by the vertically oriented honeycomb structure. With a sc of 0.27 the structure provides almost $43 \%$ more shading than the optimized honeycomb structure. On southwest, the optimized honeycomb structure provides $15 \%$ more shading than the vertically orientated honeycomb structure, which provides the second best sc. Similar results are seen for west, where the optimized honeycomb shading structure provides a sc of 0.29 , which is $21.2 \%$ better than the second best shading structure, again the vertically orientated honeycomb shading structure. But again, the results could also show that the optimized structure only provides more diffuse solar radiation than the others and thus, it simply allows a higher degree of visual comfort with full shading from March until September, the critical months with regard to high temperatures. 


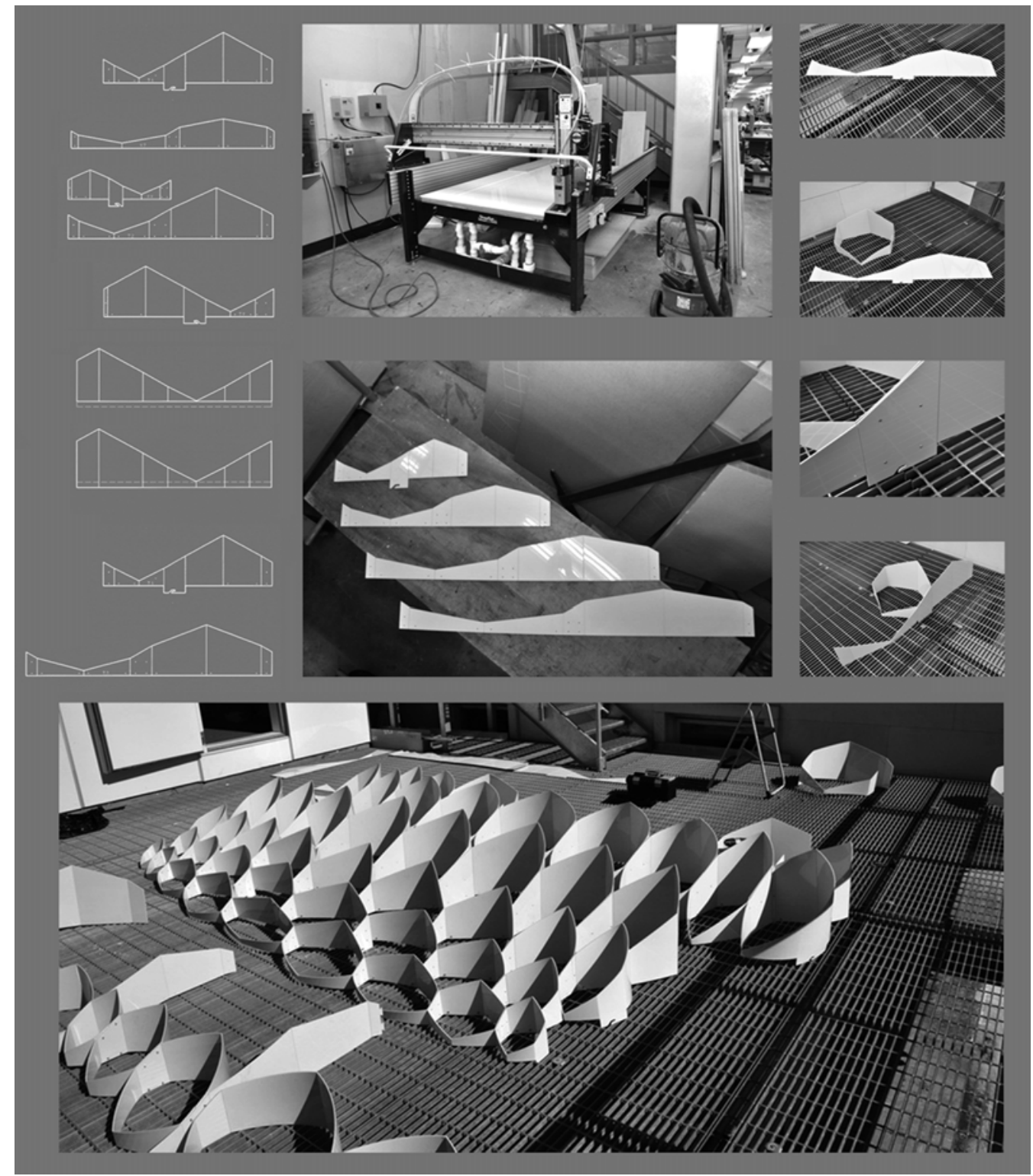

Figure 6: Construction and assembly of experimental prototype structure.

\section{DESIGN METHODS/GOALS FOR VIRTUAL LIGHT/AIR FILTER WALL}

Expanding upon the process and findings of prototype 1, prototype 2, a hybridized air/light filter wall, is proposed as a continued speculative design study. Prototype 2 was compared to the control variables of a conventional punched windows and a curtain wall system (see Figs. 9-11). An iterative software analysis process was implemented to test radiosity, daylight distribution, and resultant required energy loads for prototype 2. Using AutoCAD 2010, a single three-dimensional test house, of $40 \mathrm{~m}^{2}$, was digitally modeled, with a representative table height surface and a seating surface, 


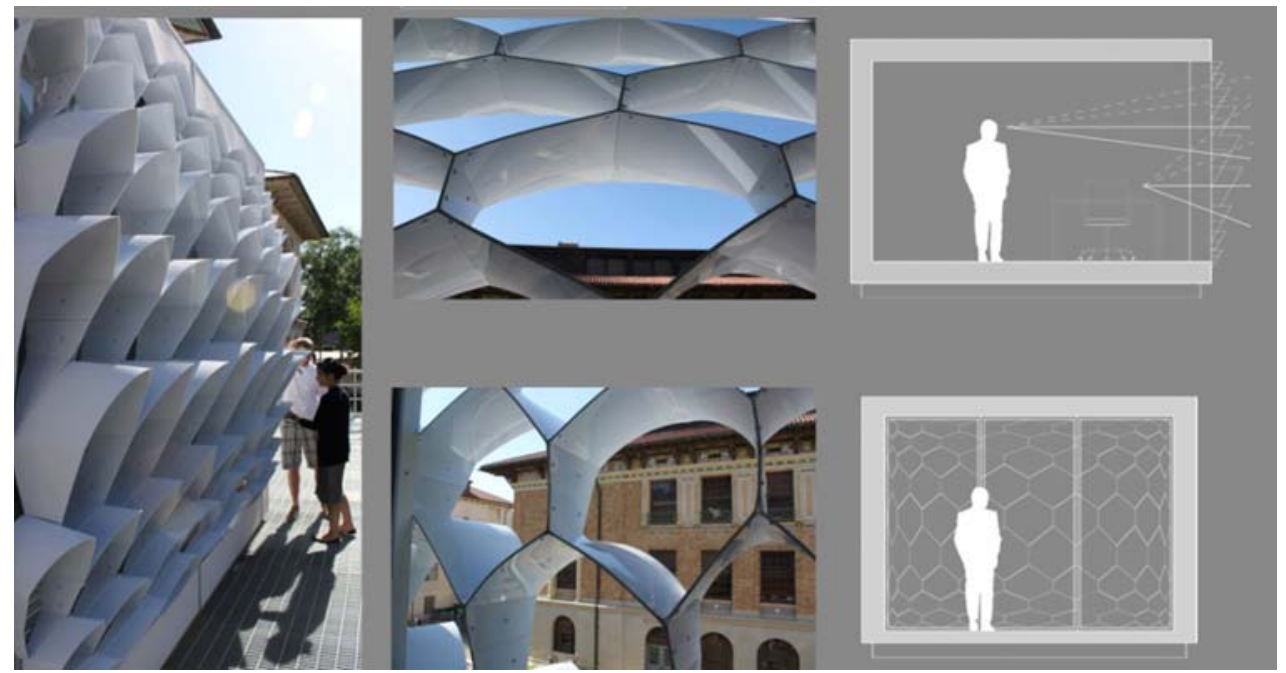

Figure 7: View of experimental prototype shading structure on Facade Laboratory.

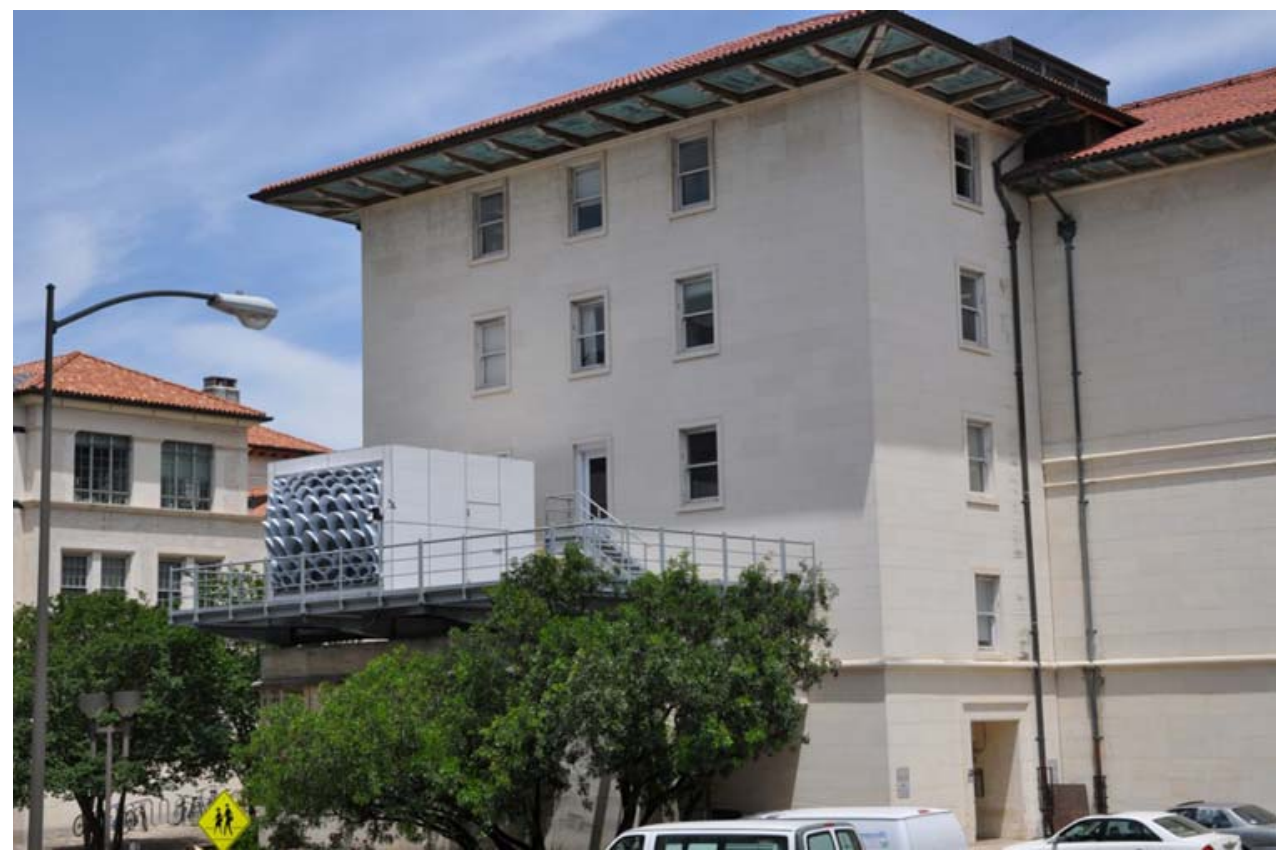

Figure 8: View of experimental prototype shading structure on Facade Laboratory.

to evaluate illuminance levels at those critical heights. A 3D Studio Max was used to simulate radiosity renderings. Most critically, Energy Plus was used as a rigorous software tool to analyze daylighting performance in a series of illuminance maps, which show precise amounts of daylight in plan. Illuminance mapping was performed to provide fine grain visual data analysis set in abstracted graph form. The digital test house experiments were set on the spring/fall equinox, 


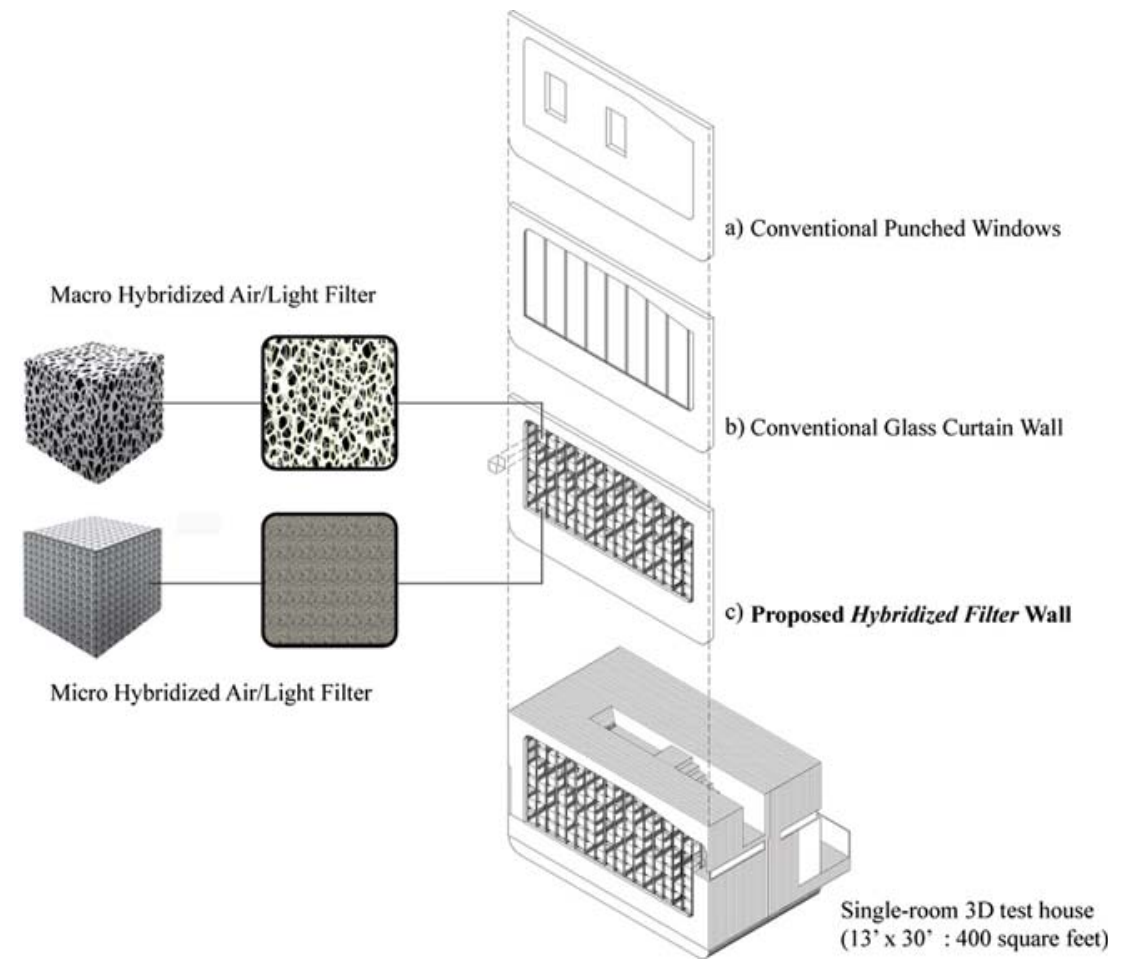

Figure 9: Facade system diagrams. (a) Conventional punched window wall, (b) conventional curtain wall, and (c) hybridized air/light filter wall (prototype 2).

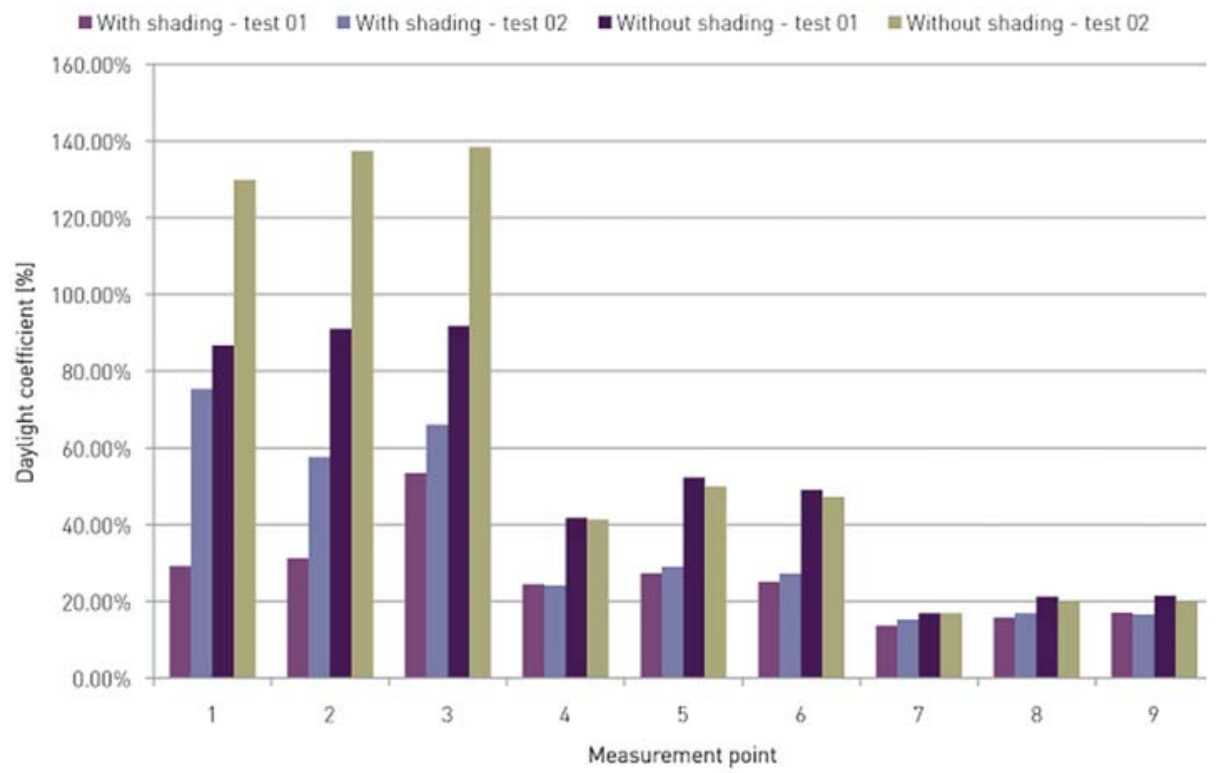

Figure 10: Comparison of daylight coefficient between shading and no shading. 

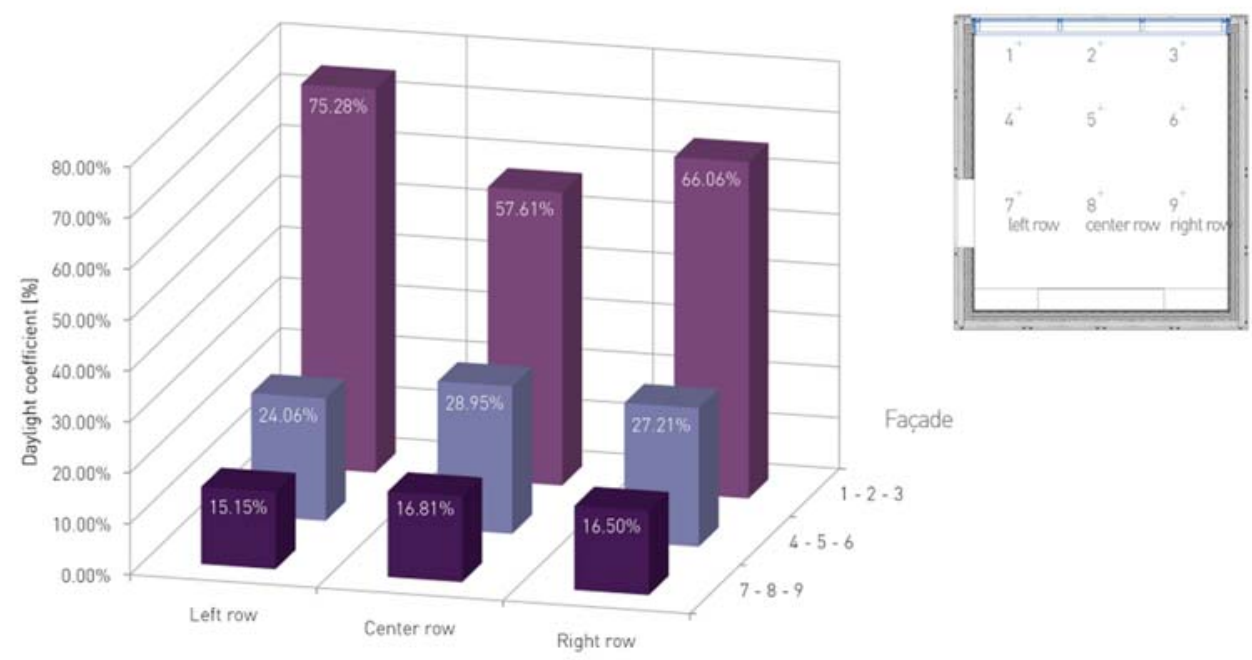

Distribution of daydight coefficients in the Thermal Lab wath shading - test 02

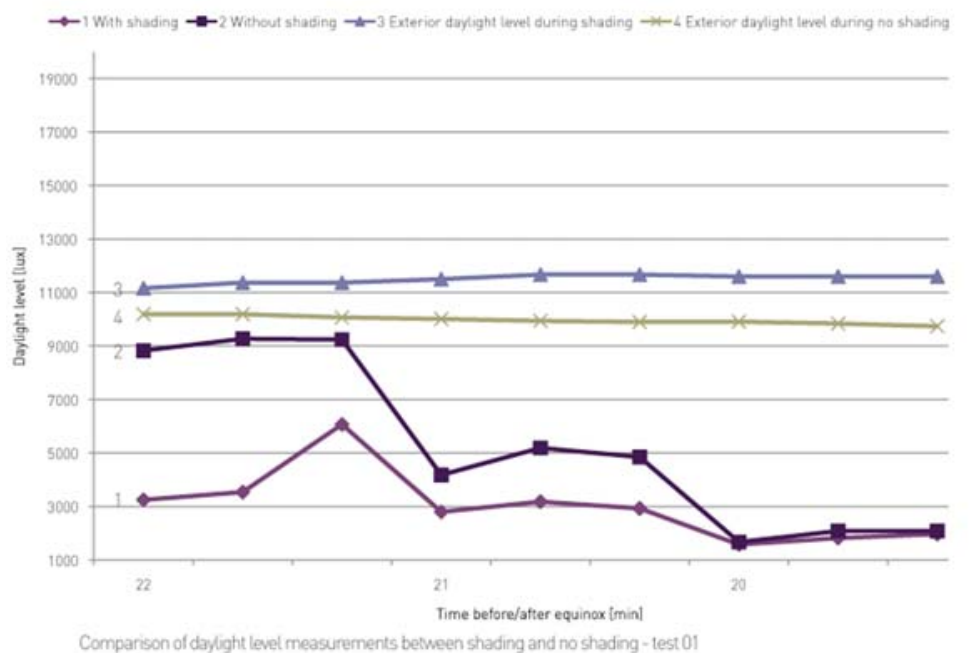

Figure 11: Effect of experimental prototype structure on daylight distribution.

at latitude 37.795 and longitude -122.394 to most closely capture an average day, at a moderate latitude in the middle of the continental United States. The test house was modeled with conventional stud wall construction, R-30 roof, and an R-19 floor. The hybridized filter panels allow $15 \%$ light transmission, and the default interior surfaces were set as a moderate level of reflectivity. This passive daylighting analysis relates to specific shading devices in case studies, such as Helmut Koster's Thermolux shading device analysis in Dynamic Daylighting [2]. The uniqueness of prototype 2 is based on its integral use of filtration devices to modulate daylight, allowing for cross ventilation in addition to light management. 


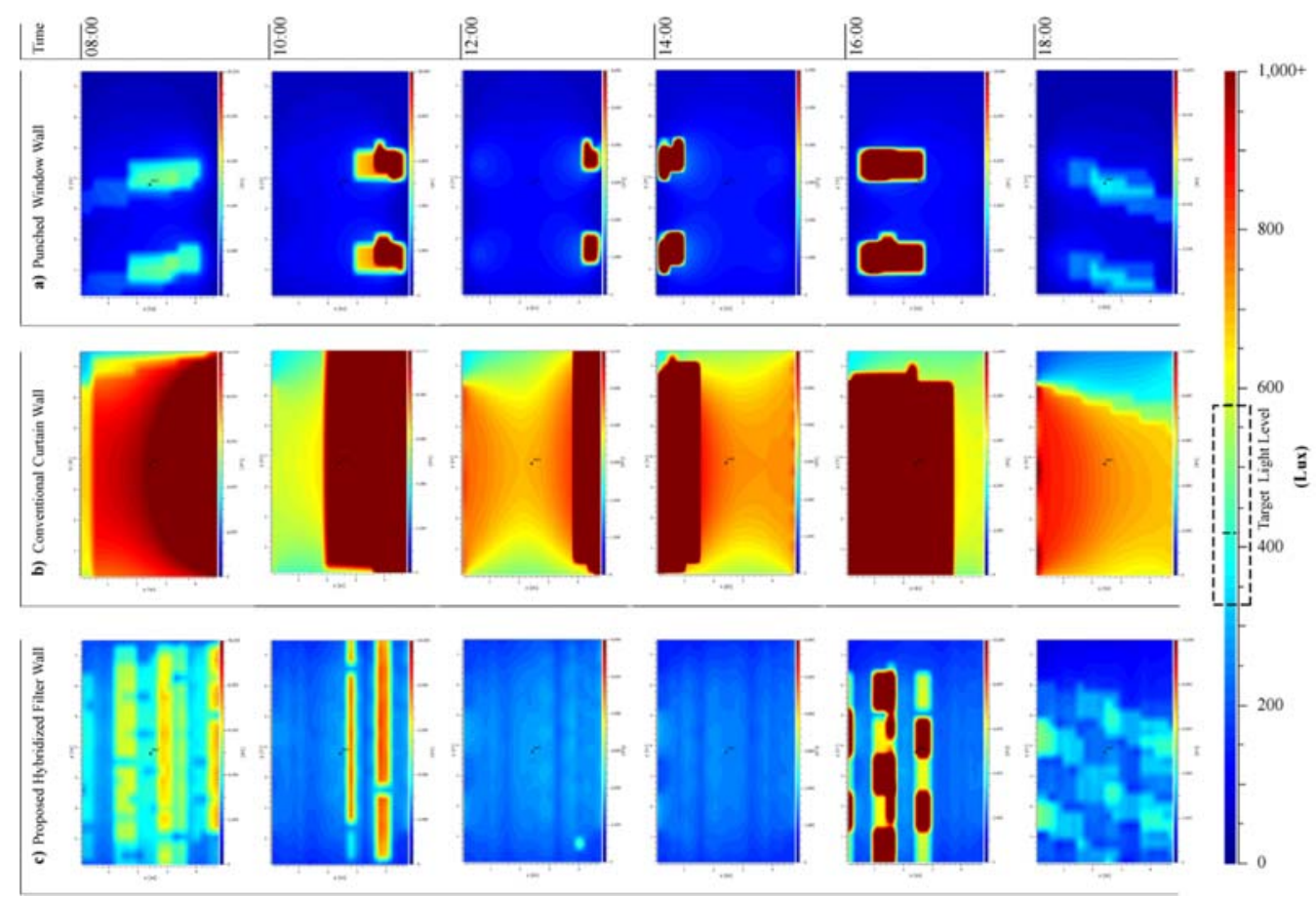

Figure 12: Illuminance simulation map results. (a) Conventional punched window wall,

(b) conventional curtain wall, and (c) hybridized air/light filter wall (prototype 2).

\section{RESULTS}

Prototypes 1 and 2 were measured individually to gauge results, using the respective parameters relating to their basis. Lux was used as the unit of measurement for light, where $~ 300-600$ Lux is considered a target quantity of interior daylight for performing a wide range of tasks (see Fig. 10). Cross ventilation is assumed to occur by natural wind and convective forces in case of the experimental hybridized wall system, although no in-depth analysis was conducted to measure the ideal amount of openings and/or area of filtration, which was considered beyond the scope of this investigation.

\subsection{Prototype 1 results}

Prototype 1 performed well in terms of daylight coefficient compared to the control condition without shading in terms of stabilization (see Fig. 12), and due to the minimized use of material, the optimized honeycomb shading structure is highly competitive with the other generic shading devices. The experimental shading device strongly distributes and controls daylight level (see Fig. 13). Ultimately, it even performs third on area of unrolled shading structure and performs best on total volume of shading structure. Even though it has a slightly larger area of visible shading structure than the honeycomb shading structure with a circumference of $4^{\prime}$, it provides a high degree of visual contact due to the enlarged openings in defined regions, which provide the same sc as smaller components. Though qualitative, it can be argued that the optimized honeycomb is more interesting and aesthetically intriguing (due to climatic specificity) than conventional louver types (see Fig. 8). 

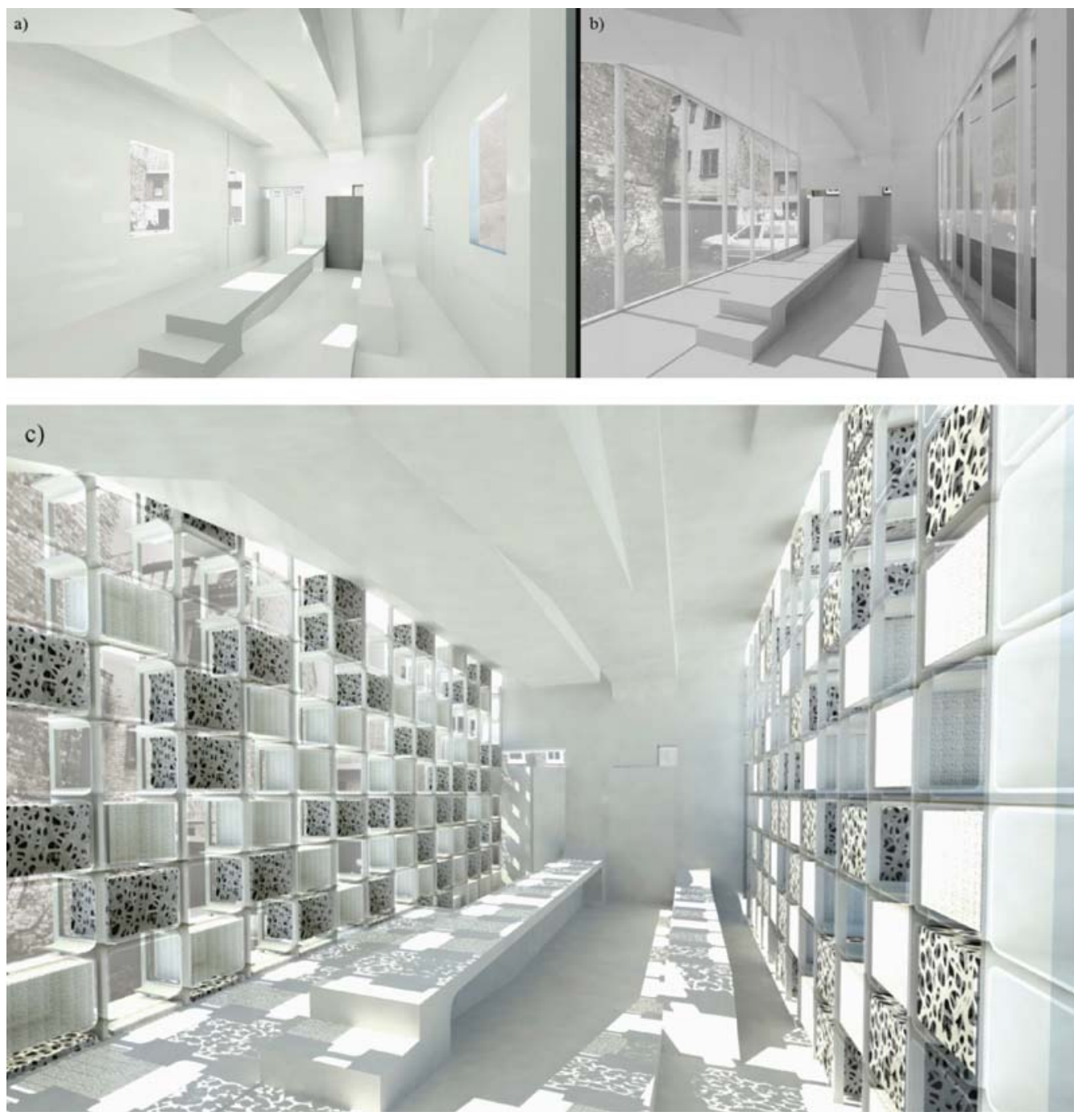

Figure 13: Radiosity rendering daylight simulations. (a) Conventional punched window wall, (b) conventional curtain wall, and (c) hybridized air/light filter wall (prototype 2).

\subsection{Prototype 2 results}

Energy Plus daylighting analysis shows that the experimental hybridized air/light filter wall (prototype 2) provides a more moderate overall illuminance and passive daylight than either of the conventional wall and glazing types. The experimental scenarios provides a gradient of various lighting conditions, to allow the occupant to choose different areas in the space for different tasks, depending on the amount of light needed or desired, and/or to allow the occupant to reside in multiple temperature zones in different areas throughout the day within the singular space, reducing the need for mechanical and artificial thermal control. 


\section{DISCUSSION}

Daylight is a versatile asset in the design process, as it can be designed to produce a variety of lighting conditions through natural modulations in intensity, diffusion, and direction over time. Research suggests that levels of natural light, which have shorter wavelengths than electric lighting, can be a suppressant of melatonin, thereby affecting the human biological system positively [7]. Although direct sunlight can result in glare issues, methods of controlling and diffusing light can alleviate such issues to produce comfort within a space.

Prototype 1 suggests that shading structures can achieve optimal daylight performance, while maximizing views and introducing novel architectural forms. Prototype 2 suggests that a hybridized filter may be a feasible answer to a common problem with cross ventilation. For example, architectural projects designed in hot, arid, desert climates would benefit from cross ventilation as air-exchange strategy, but buildings encounter the problem of inviting in the heat, sand, and pollution along with wind. In addition, if filters were applied in a skyscraper condition, an inconsistent gradient would result when increasing elevation due to shifting daylighting conditions and the potential for greater pollution at higher altitudes. Such a hybridized filter could be used to allow the movement of air but keep out the unwanted elements and also double as a partial shading device.

\section{CONCLUSIONS}

Amidst increasing pressure to improve building sustainability, there exists a dire need for collaboration between architects and engineers to optimize quantitative and qualitative building performance, including merging between the two disciplines. By increasing our quantitative understanding of the cause and effect relationship between shading device design and daylight transmission, qualitative design processes can be rigorously measured in an integrated manner, thus creating some overlap between the roles of the architect and engineer. This research suggests that there can exist a new middle working ground toward the quantifiable and qualitative design alternative building envelope design solutions with improved functional, ecological and aesthetic properties which can be adapted and applied in future developments in various climatic conditions.

The experimental honeycomb variant shading device (prototype 1) designed by Stefan Bader is a promising start, both qualitatively and quantitatively, and is indicative of the potential of the Facade Laboratory to act as a powerful experimentation tool for design studies to manage annual solar radiation and expand upon options for high performance facades by developing a variety of shading structures for building skins. The physical reality of the mock-up on the Facade Laboratory and its measured results, coupled into a design loop with simulation software, allow for an unparalleled positive synergy between the virtual and physical testing, ultimately enhancing design processes.

As prototype 2 suggests, there also exists a great capacity for further investigation on the coupling of air and light filtration. In the future, the fundamental process of air filtration may have a place in architectural design processes as early as the schematic design phase. By considering filtration as a design concept, indoor air quality issues are much more likely to be taken seriously in architectural design processes and seen as a featured device, rather than a back-of-house technical eyesore to be placed out of sight. Thus, hybridized filters on display in building facades could raise awareness of indoor air quality issues in architectural spaces. Prototype 2 could potentially become more practical if it performed triple duty as a sponge which also absorbs the water, allowing it to be collected, stored, and pumped through the facade, in turn creating a water wall that cools the air while filtering it. The sponge filaments could even contain a gas that expands when exposed to sunlight, decreasing the amount of direct light allowed in. Though development of light filtration and air filtration has occurred over time, the development of an integrated design could provide a new range of flexibility in building facades. 
The Facade Laboratory at the University of Texas at Austin School of Architecture, and the speculative design it inspires, clearly offers the opportunity to develop an integrated approach to problem-solving by interdisciplinary teams of scientists and students from architecture, engineering, natural sciences, and other fields. The value of this experimental facility will be further amplified through its dynamic and integrated use by architects, planners, designers, and engineers.

\section{ACKNOWLEDGMENTS}

Thanks to Brandon Hubbard for research and visualization assistance, to Dason Whitsett for Energy Plus modeling assistance for prototype 2, and to Natalie Ward for research and editing assistance. Most importantly, thanks to Professor Dr. Werner Lang for conception and creation of the University of Texas at Austin School of Architecture Facade Laboratory, and to Stefan Bader for designing and developing the optimized honeycomb variant shading structure (prototype 1).

\section{REFERENCES}

[1] U.S. Green Building Council, Green Building Facts, http://www.usgbc.org/ShowFile.aspx? DocumentID=5961.

[2] Koster, H. Dynamic Daylighting Architecture: Basics, systems, Projects. Basel: Birkhauser, 2004.

[3] Brown, R.C. Air Filtration: An Integrated Approach to the Theory and Applications of Fibrous Filters. Oxford: Pergamon Press, 1993.

[4] Michell, G. Architecture of the Islamic World: It's History and Social Meaning. London: Thames and Hudson, 1978.

[5] Schittich, Christian. Building Skins: Concepts, Layers, Materials. Basel: Birkhauser, 2001.

[6] Bader, S. High-performance facades for commercial buildings. M.S.S.D. Thesis, The University of Texas at Austin (USA), 229 pages, 2010.

[7] Augustin, S. Place Advantage: Applied Psychology for Interior Architecture. New Jersey: John Wiley \& Sons, Inc, 2009. 